\title{
Immersion Vaccination by a Biomimetic-Mucoadhesive Nanovaccine Induces Humoral Immune Response of Red Tilapia (Oreochromis sp.) against Flavobacterium columnare Challenge
}

\author{
Sirikorn Kitiyodom ${ }^{1}$ (D) Teerapong Yata ${ }^{2}$, Kim D. Thompson ${ }^{3, *(D)}$, Janina Costa ${ }^{3}$, Preetham Elumalai ${ }^{4}$ (D), \\ Takayuki Katagiri ${ }^{5}$, Sasithon Temisak ${ }^{6}$ (D), Katawut Namdee ${ }^{7}$ (D), Channarong Rodkhum ${ }^{8}$ (i) \\ and Nopadon Pirarat ${ }^{1, *}$
}

1 Wildlife Exotic Aquatic Animal Pathology-Research Unit, Department of Pathology, Faculty of Veterinary Science, Chulalongkorn University, Bangkok 10330, Thailand; taregust@hotmail.com

2 Biochemistry Unit, Department of Physiology, Faculty of Veterinary Science, Chulalongkorn University, Bangkok 10330, Thailand; Teerapong.Y@chula.ac.th

3 Moredun Research Institute, Pentlands Science Park, Penicuik EH26 0PZ, UK; janina.costa@moredun.ac.uk

4 School of Ocean Science and Technology, Kerala University of Fisheries and Ocean Studies, Kochi 682506, Kerala, India; preetham@kufos.ac.in

check for updates

Citation: Kitiyodom, S.; Yata, T.; Thompson, K.D.; Costa, J.; Elumalai,

P.; Katagiri, T.; Temisak, S.; Namdee,

K.; Rodkhum, C.; Pirarat, N. Immersion Vaccination by a Biomimetic-Mucoadhesive Nanovaccine Induces Humoral Immune Response of Red Tilapia (Oreochromis sp.) against Flavobacterium columnare Challenge. Vaccines 2021, 9, 1253. https:// doi.org/10.3390/vaccines9111253

Academic Editors: Beatriz Novoa, Patricia Pereiro and François Meurens

Received: 10 September 2021

Accepted: 27 October 2021

Published: 29 October 2021

Publisher's Note: MDPI stays neutra with regard to jurisdictional claims in published maps and institutional affiliations.

Copyright: (c) 2021 by the authors. Licensee MDPI, Basel, Switzerland. This article is an open access article distributed under the terms and conditions of the Creative Commons Attribution (CC BY) license (https:/ / creativecommons.org/licenses/by/ $4.0 /)$.
5 Laboratory of Fish Health Management, Course of Aquatic Biosciences, Tokyo University of Marine Science and Technology, Tokyo 108-8477, Japan; takakata@kaiyodai.ac.jp

6 Bio Analysis Group, Chemical Metrology and Biometry Department, National Institute of Metrology (NIMT), Pathum Thani 12120, Thailand; sasithont@nimt.or.th

7 National Nanotechnology Center (NANOTEC), National Science and Technology Development Agency (NSTDA), Pathum Thani 12120, Thailand; katawut@nanotec.or.th

8 Department of Microbiology, Faculty of Veterinary Science, Chulalongkorn University, Bangkok 10330, Thailand; Channarong.R@chula.ac.th

* Correspondence: Kim.Thompson@moredun.ac.uk (K.D.T.); Nopadon.P@chula.ac.th (N.P.)

\begin{abstract}
Immersion vaccination with a biomimetic mucoadhesive nanovaccine has been shown to induce a strong mucosal immune response against columnaris disease, a serious bacterial disease in farmed red tilapia caused by Flavobacterium columnare. However, the induction of a systemic immune response by the vaccine is yet to be investigated. Here, we examine if a specific humoral immune response is stimulated in tilapia by a biomimetic-mucoadhesive nanovaccine against Flavobacterium columnare using an indirect-enzyme-linked immunosorbent assay (ELISA), serum bactericidal activity (SBA) and the expression of immune-related genes within the head-kidney and spleen, together with assessing the relative percent survival of vaccinated fish after experimentally infecting them with F. columnare. The anti-IgM antibody titer of fish at 14 and 21 days post-vaccination was significantly higher in chitosan complex nanoemulsion (CS-NE) vaccinated fish compared to fish vaccinated with the formalin-killed vaccine or control fish, supporting the serum bactericidal activity results at these time points. The cumulative mortality of the unvaccinated control fish was $87 \%$ after challenging fish with the pathogen, while the cumulative mortality of the CS-NE vaccinated group was $24 \%$, which was significantly lower than the formalin-killed vaccinated and control fish. There was a significant upregulation of $\operatorname{IgM}, \operatorname{IgT}$, TNF $\alpha$, and IL1- $\beta$ genes in the spleen and kidney of vaccinated fish. Significant upregulation of $I g M$ and IgT genes was observed in the spleen of CS-NE vaccinated fish. The study confirmed the charged-chitosan-based mucoadhesive nanovaccine to be an effective platform for immersion vaccination of tilapia, with fish generating a humoral systemic immune response against columnaris disease in vaccinated fish.
\end{abstract}

Keywords: red tilapia; systemic immune response; columnaris disease; nano-immersion vaccine 


\section{Introduction}

Flavobacterium columnare, a gram-negative, filamentous, thin rod bacterium, with or without yellow rhizoid colony formation, is a serious pathogenic bacterium causing columnaris disease in intensively farmed tilapias worldwide [1,2]. Flavobacterium columnare infections can lead to skin lesions, fin decay, and gill tissue damage, contributing to significant economic losses and a high mortality rate [3,4]. The virulence of $F$. columnare is demonstrated by its ability to adhere to mucosal surfaces, gliding motility, biofilm formation, and capsule production, which have been associated with its rhizoid morphotype [5]. The colonization of the bacterium to the mucosal surfaces of the fish (skin and gills) is an important step in initiating the infection, disease severity, and progression, and the typical pathological characteristics associated with columnaris disease. Vaccination against columnaris disease has been trialed in a variety of fish species. However, only low or partial protection has been reported for columnaris vaccines administered by injection or immersion using formalin-killed whole cell preparations in coho salmon Oncorhynchus kisutch [6], channel catfish Ictalurus punctatus [7,8], eels [9], carp Cyprinus carpio [10], and tilapia Oreochromis niloticus [11,12]. Among the vaccination delivery routes used to administer vaccines to fish, immersion vaccination is considered to be the most suitable for delivering columnaris vaccines to the mucosal tissues to confer a protective mucosal immune response to protect fish against the disease. Nevertheless, this approach has been impeded by the fact that the effectiveness of antigen absorption by mucosal tissues is limited and the potency of induction of protective immune responses can be low and short in duration. Our previous study demonstrated the use of a biomimetic-mucoadhesive nanovaccine that allows better adsorption of antigens to the mucosal surfaces of fish $[13,14]$. Strong mucosal immunity was triggered by the vaccine, inducing an immune cascade at the mucosal site and in the mucosal associated lymphoid tissue (MALT) following immersion immunization [4]. However, the ability of this vaccine to activate a systemic humoral immune response has not yet been elucidated. The aim of the present study was to investigate the specific humoral immune response stimulated in tilapia by the biomimetic-mucoadhesive nanovaccine against $F$. columnare, using an indirect-enzyme linked immunosorbent assay (ELISA) to measure serum antibody responses, serum bactericidal activity (SBA), and the expression of immune-related genes within the head-kidney and spleen. The in-house ELISA developed in the study seems suitable for monitoring the specific humoral response in tilapia against the columnaris disease.

\section{Materials and Methods}

The use of animals in experimentation for this study was officially approved by the Institutional Biosafety Committee and the Institutional Animal Care and Use Committee of Faculty of Veterinary Science, Chulalongkorn University (IBC1831052; IACUC1831020). All procedures were carried out in accordance with university guidelines and regulations as well as policies governing biosafety procedures.

\subsection{Fish and Experimental Conditions}

Six hundred red tilapia (Oreochromis sp.) with an average weight of $100 \mathrm{~g}$, were acclimatized for 10 days and randomly placed in four 200-L fiberglass tanks (150 fish per tank) for the four treatments described below. The tanks were maintained under continuous aeration at $25-28^{\circ} \mathrm{C}, 5.8-6.8 \mathrm{ppm}$ dissolved oxygen (DO), $\mathrm{pH} 7.5-8$ and less than $0.1 \mathrm{mg} / \mathrm{L}$ of total ammonia throughout the experiment. Experimental fish were fed twice a day and water was changed up to $50 \%$ every second day.

\subsection{Bacteria and Vaccine Preparation}

Flavobacterium columnare isolate (F-K17/1, GenBank accession no. MW362353), used in our previous studies, was selected based on its ability to form rhizoid colonies, its high virulence in clinical outbreaks and belonging to genetic group 4 determined by $16 \mathrm{~s}$ rRNA phylogenetic analysis. Bacterial cultures used in the vaccine preparation were grown 
in Tryptone Yeast Extract Salts Agar (TYES) broth at $25-28{ }^{\circ} \mathrm{C}$ for $48 \mathrm{~h}$. Bacteria were killed with $0.2 \%$ formalin and incubated at $4{ }^{\circ} \mathrm{C}$ for $20 \mathrm{~h}$. Bacterial cells were collected by centrifuging at $3000 \times g$ at $4{ }^{\circ} \mathrm{C}$ for $30 \mathrm{~min}$. Formalin-killed bacteria were washed three times with phosphate-buffered saline (PBS, pH 7.2) and the bacterial concentration of the vaccine preparation was adjusted to $10^{8} \mathrm{CFU} \mathrm{mL}^{-1}$. Formulation of the vaccine was carried out according to Kitiyodom et al. (2019) [13]. In brief, to prepare the whole cell killed bacterial vaccine (WC), an aliquot of bacterial cells $(15 \% w / w)$ was mixed with PBS $(85 \%$ $w / w)$. To prepare the chitosan complex nanoemulsion (CS-NE), an aliquot of bacterial cells $\left(10^{10} \mathrm{CFU} \mathrm{\textrm {mL } ^ { - 1 }}\right)$ was sonicated at $40 \%$ amplitude for $10 \mathrm{~min}(30 \% \mathrm{w} / \mathrm{w})$ was mixed with $6 \%(w / w)$ of polyoxyethylene (20) sorbitan monolaurate, $2 \%(w / w)$ of medium chain triglycerides (MCTs) and $62 \%(w / w)$ of water. The mixture was homogenized using an ultrasonic homogenizer at $40 \%$ amplitude for $5 \mathrm{~min}$. The complexation of the nanoemulsion with chitosan was performed by adding $1 \%$ of chitosan (previously dissolved in $1 \%$ acetic acid) to the nano-emulsion at a ratio of 1:1 $(v / v)$. The mixture was stirred for $1 \mathrm{~h}$ at room temperature. The CS-NE schematic diagram and image of scanning electron microscope (SEM) of the resulting nanoparticles are shown in Figures 1 and 2. The final bacterial concentration in WC and CS-NE vaccine was $10^{8} \mathrm{CFU} \mathrm{mL}^{-1}$.

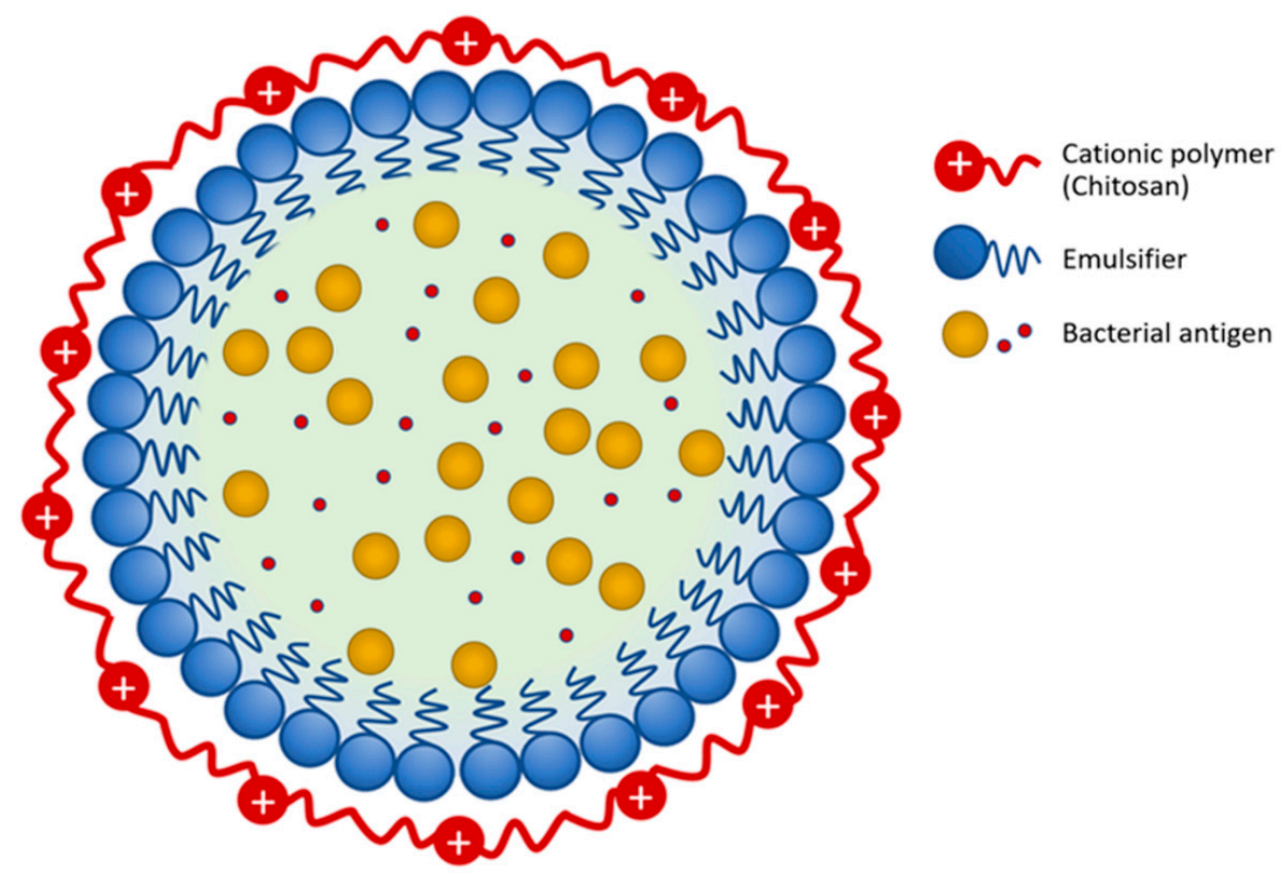

Figure 1. Schematic diagram of the in chitosan complex nanoemulsion vaccine.

a.

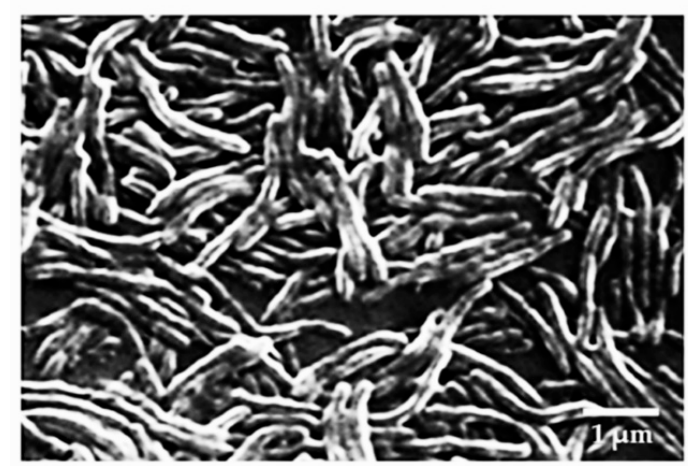

b.

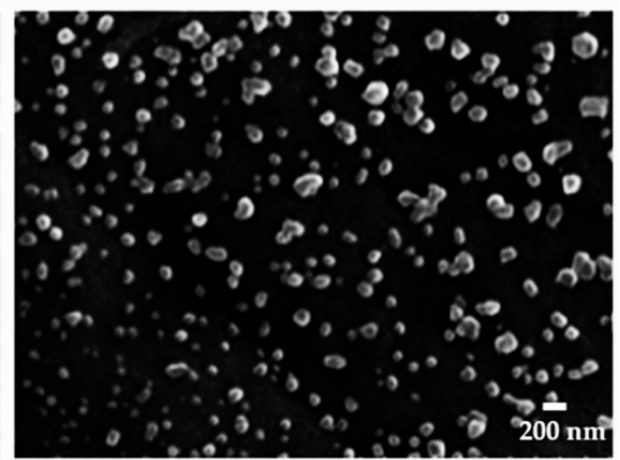

Figure 2. (a) Scanning electron microscopy (SEM) of the surface morphology of formalin killed vaccines, Scale bar $=1 \mu \mathrm{m}$. and (b) SEM images of CS-NE vaccine, scale bar $=200 \mathrm{~nm}$. 


\subsection{Vaccination and Vaccine Efficacy Test}

Red tilapia (100 g) were divided into four groups: (1) whole cell killed bacteria vaccine (WC); (2) nanovaccine (CS-NE); (3) polymer blank (polymer), and (4) PBS (control) (150 fish per group, 1 tank group ${ }^{-1}$ ). Fish were immersed in the vaccine solutions, diluted 1:100 with tank water $\left(10^{6} \mathrm{CFU} \mathrm{mL}{ }^{-1}\right)$ for $30 \mathrm{~min}$ with aeration. After vaccination, fish were transferred into fiberglass tanks containing $200 \mathrm{~L}$ of water. At 1, 3, 14, and 21 days after vaccination, blood was collected from 6 fish per group by caudal puncture using a $25 \mathrm{G} \times 16 \mathrm{~mm}$ needle and $1 \mathrm{~mL}$ syringe, and allowed to clot $1 \mathrm{~h}$ at $25^{\circ} \mathrm{C}$. The serum was collected following centrifugation at $3000 \times g$ for $10 \mathrm{~min}$ and stored at $-20^{\circ} \mathrm{C}$ until analyzed [11]. After 30 days post-vaccination (dpv), fish (30 from each group, 3 replicate tanks) were challenged with a lethal concentration $80\left(\mathrm{LC}_{80}\right)$ of a virulent strain of F-K17/1 by immersion for $1 \mathrm{~h}$. The cumulative mortality, and survival rates were recorded for 14 days after challenge and the relative percent survival (RPS) was calculated, RPS $=1-($ mortality rate of vaccinated fish/mortality rate of control fish $) \times 100$ [15]

\subsection{Serum Bactericidal Activity (SBA)}

The serum from fish was prepared as described above. Flavobacterium columnare colonies were centrifuged and the pellet was washed and suspended in PBS. The optical density of the bacterial suspension was adjusted to an optical density of 0.8 at $540 \mathrm{~nm}$ $\left(1 \times 10^{6} \mathrm{CFU} / \mathrm{mL}\right)$. A volume of $2 \mu \mathrm{L}$ of bacterial suspension was mixed with $20 \mu \mathrm{L}$ of fish serum in each group and incubated at room temperature for $1 \mathrm{~h}$. Phosphate buffer saline was used in place of the serum for the negative control. After the incubation, the number of viable bacteria were determined as colony forming units (CFU)/ $\mathrm{mL}$ by plating the bacterial suspension onto TYES for $48 \mathrm{~h}$ at $28^{\circ} \mathrm{C}$. The bactericidal rate was calculated as follows: ( 1 - the number of viable bacteria after serum treatment/the number of viable bacteria after PBS treatment) $\times 100 \%[16]$.

\subsection{Enzyme-Linked Immunosorbent Assay (ELISA)}

Antigen preparation: Flavobacterium columnare strain FK17/1 was cultured in TYES broth for $48 \mathrm{~h}$ and harvested by centrifuge at $10,000 \times g 4^{\circ} \mathrm{C}$ for $20 \mathrm{~min}$. The bacterial cells were washed three times with PBS and then resuspended in PBS. The bacterial solution was sonicated on ice at an amplitude of $45 \mathrm{~Hz}$ for $10 \mathrm{~min}$. The total protein content of the supernatant was measured using a Nanodrop 1000 spectrophotometer (Thermo Scientific, Waltham, MA, USA), with bovine serum albumin (BSA) used as a standard [11,17]. Stock antigen preparations were stored at $-20^{\circ} \mathrm{C}$ until used.

ELISA procedure: The ELISA 96-well microplates (Costar, Elmira, NY, USA) were coated with $100 \mu \mathrm{L}$ of $F$. columnare antigen in coating antigen ( $0.05 \mathrm{M}$ sodium carbonate buffer $\mathrm{pH}$ 9.6) overnight at $4{ }^{\circ} \mathrm{C}$. Unbound antigen was discarded, and the plates were washed three times with washing buffer (PBS containing $0.05 \%$ Tween $20 \mathrm{pH} 7.3$ ). Nonspecific bindings were blocked by adding $250 \mu \mathrm{L}$ of blocking solution $(1 \% w / v$ BSA in PBS pH 7.2) at $22{ }^{\circ} \mathrm{C}$ for $2 \mathrm{~h}$. After incubation, the plates were washed three times with washing buffer. A two-fold serial dilution of serum samples was prepared in PBS and $100 \mu \mathrm{L}$ of diluted sera was added to each well. After an overnight incubation at $4{ }^{\circ} \mathrm{C}$, the plates were washed five times with washing buffer and were incubated for $5 \mathrm{~min}$ on last wash. A mouse anti-tilapia (O. niloticus) IgM monoclonal antibody (Aquatic Diagnostics Ltd., Oban, UK) was used to quantify the specific antibody response in fish sera, diluted in PBS according to the manufactures protocol, using $100 \mu \mathrm{L}$ well ${ }^{-1}$ and incubating at $22{ }^{\circ} \mathrm{C}$ for $1 \mathrm{~h}$. The plates were washed five times with washing buffer, incubating for $5 \mathrm{~min}$ on the last wash. After which, $100 \mu \mathrm{L}$ of anti-mouse IgG- Horseradish peroxidase HRP (KPL, Gaithersburg, MD, USA) was used as the secondary antibody at a 1:2000 dilution, and the plate was then incubated at $22{ }^{\circ} \mathrm{C}$ for $1 \mathrm{~h}$. The plates were washed five times with washing buffer and were incubated for $5 \mathrm{~min}$ on the last wash. Tetramethylbenzidine chromogen was added to each well $\left(100 \mu \mathrm{L}^{-1}\right)$ and incubated for $5 \mathrm{~min}$ at $22^{\circ} \mathrm{C}$. The reaction was then stopped by adding $50 \mu \mathrm{L}$ stop solution to each well. The absorbance of the plates was read 
using a microplate reader at $450 \mathrm{~nm}$. Results are reported as optical density (OD) at $450 \mathrm{~nm}$. All samples and controls were run in duplicate.

Standardization of the indirect ELISA method: The indirect ELISA conditions were standardized by chessboard titration using serial dilutions of sonicated F. columnare cells tested against serial dilutions of positive and negative tilapia sera [17]. The antigen was coated onto the ELISA plate using bacterial concentrations of 1.25, 2.5, 5.0, 10.0, and $20.0 \mu \mathrm{g} / \mathrm{mL}$. Tilapia sera were diluted with PBS at dilutions of 1:20, 1:40, 1:80, 1:160, 1:320, 1:640, and 1:1280. The mouse anti-tilapia IgM monoclonal antibody was also diluted with PBS at dilutions of 1:4000. The chessboard titration method was conducted using sera from tilapia challenged with F. columnare as positive samples and non-challenged tilapia as negative samples. The optical density values derived from the method were then calculated (Supplementary Table S1).

Calculation of cut-off value: The cut-off value was obtained by measuring the optical density (OD) at a wavelength of $450 \mathrm{~nm}$. The cut-off OD values were calculated from the mean of the negative control (15 fish, 2 replicates) plus 3 standard deviations, as described previously [17]. Screened fish serum with an OD value greater than the cut-off value were considered as seropositive. Fish sera with an OD value lower than cut-off value were considered as seronegative.

The optimal conditions for the ELISA were as follows: the sonicated extract antigen was used at $2.5 \mu \mathrm{g} / \mathrm{mL}$ in coating buffer, incubating with the antigen overnight, 1:160 diluted tilapia serum in blocking buffer (1\% BSA in PBS) for incubation overnight, 1:4000 diluted of the mouse anti-tilapia IgM monoclonal antibody for $1 \mathrm{~h}$ and 1:2000 diluted of the anti-mouse IgG- HRP conjugated for $1 \mathrm{~h}$. Average optical density values at $450 \mathrm{~nm}$ of the negative sera were 0.167 and the standard deviation was 0.027 . From this, the cut-off point of the indirect ELISA was calculated with the mean of the negative control plus three standard deviations [17] and the value was set to 0.2480 . For the interpretation, tilapia sera with an OD value higher than the cutoff value were determined as F. columnare antibody positive. Tilapia sera with an OD value lower than the cutoff value were considered as F. columnare antibody negative. A titration curve for serum appeared linear across the dilution range used for the study (Figure 3). The mean OD in the adsorbed seronegative pool ( $\mathrm{n}=15$ fish, Supplementary Table S2) was $0.167 \pm 0.027$ and the seropositive was $1.410 \pm 0.018$ at the 1:160 dilution.

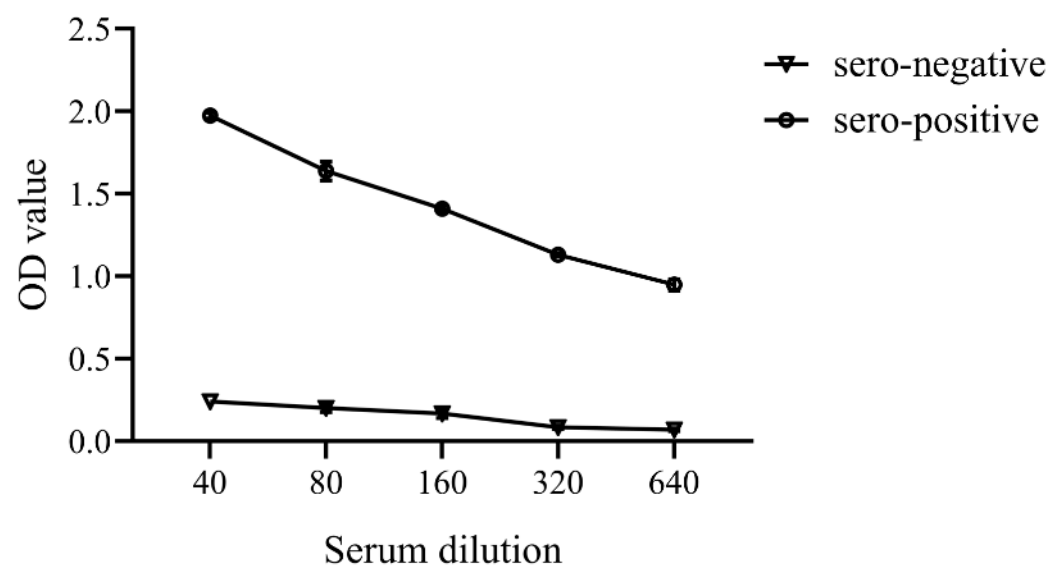

Figure 3. A titration curve for Flavobacterium columnare seropositive and seronegative serum samples (mean \pm SEM) from tilapia appeared linear across the serum dilution range used in the indirect ELISA.

\subsection{Gene Expression Determined by RT-qPCR}

Spleens and head kidney were also collected at 1, 3, 14, and $21 \mathrm{dpv}$ from 6 fish per group for gene expression by real time quantitative reverse transcription-polymerase chain reaction (RT-qPCR). Fish were euthanized with an overdose of clove oil anesthetic before tissue sampling for RT-qPCR. Tissues were placed immediately in RNAlater (SigmaAldrich, Darmstadt, Germany) and stored at $4{ }^{\circ} \mathrm{C}$ overnight. RNA-later was removed 
and tissues were stored at $-80{ }^{\circ} \mathrm{C}$ until RNA was extracted. For this, 30 to $40 \mathrm{mg}$ of gill tissue sample was used, from which RNA was extracted using a RNeasy Minikit (QIAGEN, Hilden, Germany) following the manufacturer's instructions. RNA samples were stored at $-80^{\circ} \mathrm{C}$ until analyzed. RNA quantity and quality were determined using the Nanodrop ND-1000 Spectrophotometer (Thermo Fisher Scientific, Waltham, MA, USA) and adjusted to a final concentration of $1 \mu \mathrm{g} \mu \mathrm{L}^{-1}$. The mRNA was converted to complementary DNA (cDNA) using a Quantinova Reverse Transcription kit (QIAGEN) according to the manufacture's protocol. The cDNA was analyzed for the expression of immune related genes (Table 1), including interleukin-1 (IL-1), tumor necrosis factor alpha (TNF $\alpha$ ), MHC class $1(M H C I)$, immunoglobulin $\mathrm{M}(\operatorname{IgM})$, and immunoglobulin $\mathrm{T}$ (IgT). In this study, we proposed that a biomimetic mucoadhesive nanoplatform could facilitate the bacterial antigen to potentiate the mucosal and systemic immune responses at the very beginning of the induction of the immune response. The interaction between innate and adaptive immunity was the topic of interest. The immune related genes associated with innate cytokines (IL1 $\beta, T N F-\alpha$ and MHC I) were included. Another point regarding the MHCI gene, is that the size of the nanovaccine was as small as the intracellular organisms and lipid composition in nanoparticles can induce $\mathrm{T}$ cell response, as suggested by many researchers. Activation of intracellular signaling of MHC I by the nanovaccine was also included. IgT and IgM genes expression were selected to determine the systemic immune response, along with the IgM antibody titer response. We lack specific gene and antibody markers for differentiating $\mathrm{T}$ and $\mathrm{B}$ cell types in tilapia.

Table 1. Primers used in RT-qPCR.

\begin{tabular}{|c|c|c|c|c|}
\hline Gene & Target & $\begin{array}{c}\text { Sequence } \\
\text { Forward/Reverse }\left(5^{\prime}-3^{\prime}\right)\end{array}$ & Product (bp) & Reference \\
\hline $\begin{array}{l}\beta \text {-actin F } \\
\beta \text {-actin R }\end{array}$ & Housekeeping gene & $\begin{array}{l}\text { AAGGACCTGTACGCCAACAC } \\
\text { ACATCTGCTGGAAGGTGGAC }\end{array}$ & 196 & [18] \\
\hline $\begin{array}{l}\text { TNF } \alpha \mathrm{F} \\
\mathrm{TNF} \alpha \mathrm{R}\end{array}$ & $\begin{array}{l}\text { Inflammation } \\
\text { related gene }\end{array}$ & $\begin{array}{l}\text { CTCACAGATAGCGGCATCAA } \\
\text { CCTGGGCTCTCTCTGTGTTC }\end{array}$ & 190 & [18] \\
\hline $\begin{array}{l}\text { MHC Ii } \beta \text { F } \\
\text { MHC Ii } \beta \text { R }\end{array}$ & Adaptive immune-related gene & $\begin{array}{l}\text { TCAGCACAGCAGATGGATTC } \\
\text { GCCTGCTTCACTCCAAACTC }\end{array}$ & 175 & [18] \\
\hline $\begin{array}{l}\text { IL-1 } \beta \text { F } \\
\text { IL-1 } \beta \text { R }\end{array}$ & Adaptive immune-related gene & $\begin{array}{l}\text { AAGATGAATTGTGGAGCTGTGTT } \\
\text { AAAAGCATCGACAGTATGTGAAAT }\end{array}$ & 175 & [4] \\
\hline $\begin{array}{l}\text { IgM-F } \\
\text { IgM-R }\end{array}$ & Adaptive immune-related gene & $\begin{array}{l}\text { TGGTACTGGGGGTCAAACAT } \\
\text { TAAGCGATCCATTCCAGTCC }\end{array}$ & 156 & [18] \\
\hline $\begin{array}{l}\text { IgT-F } \\
\text { IgT-R }\end{array}$ & Adaptive immune-related gene & $\begin{array}{l}\text { AGACACACCAGAGTGATTTCAT } \\
\text { AGACACACCAGAGTGATTTCATCAG }\end{array}$ & 78 & {$[4]$} \\
\hline
\end{tabular}

The RT-qPCR was performed in 96-well plates using Luna ${ }^{\circledR}$ Universal qPCR master mix (New England Biolab Inc., Ipswich, MA, USA) according to the manufacturer's instructions. Individual $20 \mu \mathrm{L}$ reactions consisted of $10 \mu \mathrm{L}$ Luna ${ }^{\circledR}$ Universal qPCR master mix and cDNA diluted 1:10 as the template. The optimal annealing temperature for all primers was determined using the thermal gradient feature of the CFX96 Real-time PCR detection system (Bio-Rad Laboratories Inc., Hercules, CA, USA). The cycling profile was as follows: enzyme activation was carried out at $95{ }^{\circ} \mathrm{C}$ for $1 \mathrm{~min}$, followed by 45 cycles of denaturing at $95^{\circ} \mathrm{C}$ for $15 \mathrm{~s}$, and annealing and primer extension at 55 and $60{ }^{\circ} \mathrm{C}$ for 30 s. $\beta$-actin was used as an internal control for cDNA normalization. Gene expression was calculated relative to the $\beta$-actin using the $2-\Delta \Delta \mathrm{Ct}$ method $[19,20]$. The gene expression data were normalized to the reference genes $\beta$-actin and expressed as a comparison of vaccinated fish relative to control fish [18,21-23]. The amplification efficiency of all primer pairs was assessed before performing the RT-qPCR analysis with an average amplification efficiency of $90.01-114.87 \%$ using the equation: $\mathrm{E}=-1+10^{(-1 / \text { slope })}$. 


\subsection{Statistical Analysis}

All analyses were performed with GraphPad Prism Software (Version 8.0), Inc. (San Diego, CA, USA). Normality was checked using the Shapiro-Wilk test. The mean $\pm \mathrm{SE}$ and analyzed with ANOVA followed by post-hoc Bonferroni's test for multiple comparisons: among groups at each time point and among trial periods within each group. A value of $p<0.05$ was regarded as statistically significant.

\section{Results}

\subsection{Vaccine Efficacy}

No fish died in any of the groups during the 30 days post-immersion vaccination. After challenging fish with $F$. columnare by immersion at 30 days post vaccination (dpv), the onset of mortality was observed during the early phase (1-5 days) of infection in all vaccinated and non-vaccinated fish. The moribund fish exhibited a clinical sign of skin color change, lesion on the body, hemorrhages, and/or deteriorated tail. In order to assess the vaccine's efficacy, an RPS value greater than $60 \%$ was considered to be a protective effect from the vaccination $[13,24]$. The percentage survival of vaccinated and control fish after challenge is shown in Figure 4; the RPS value of CS-NE group was the highest and greater than 72. However, a group vaccinated with whole-cell bacteria had an RPS value of 43. The mortality in the non-vaccinated fish was $87 \%(\mathrm{RPS}=0)$.

\section{0 days-post vaccination}

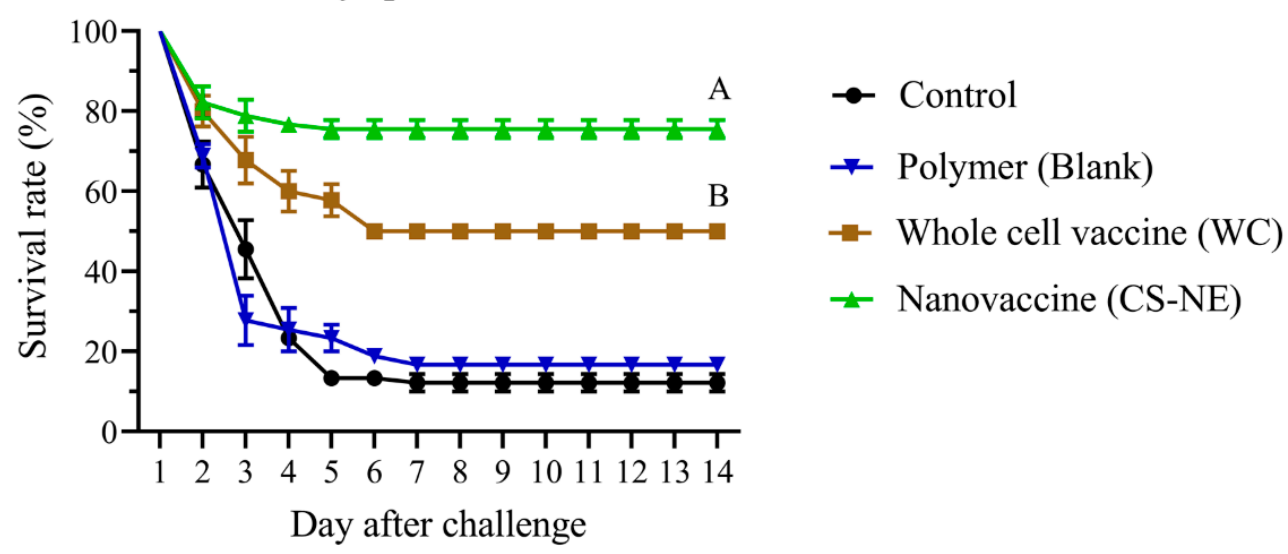

Figure 4. The percentage survival in vaccinated fish after immersion challenge with $1 \times 10^{7} \mathrm{CFU} / \mathrm{mL}$ F. columnare (strain F-K17/1), i.e., non-vaccinated, polymer, WC and CS-NE groups (30 from each group, 3 replicate tanks). The CS-NE vaccinated fish showed significantly higher levels of survival. Different capital letters indicate significant differences $(p<0.05)$ among groups at 14 days postchallenge. One-way analysis of variance, and repeated measures analysis of variance followed by Bonferroni's multiple comparison test were used for statistical analysis.

\subsection{Serum Bactericidal Activity (SBA)}

Serum bactericidal activity was the lowest in PBS and the highest in CS-NE group. The SBA of sera from CS-NE vaccinated fish was significantly elevated above that of the WC and control groups at $1,3,14$, and $21 \mathrm{dpv}(p<0.05)$ (Figure 5, Supplementary Table S3). The number of bacterial colonies obtained after treatment with sera from the CS-NE and WC groups was significantly lower than the control groups. 


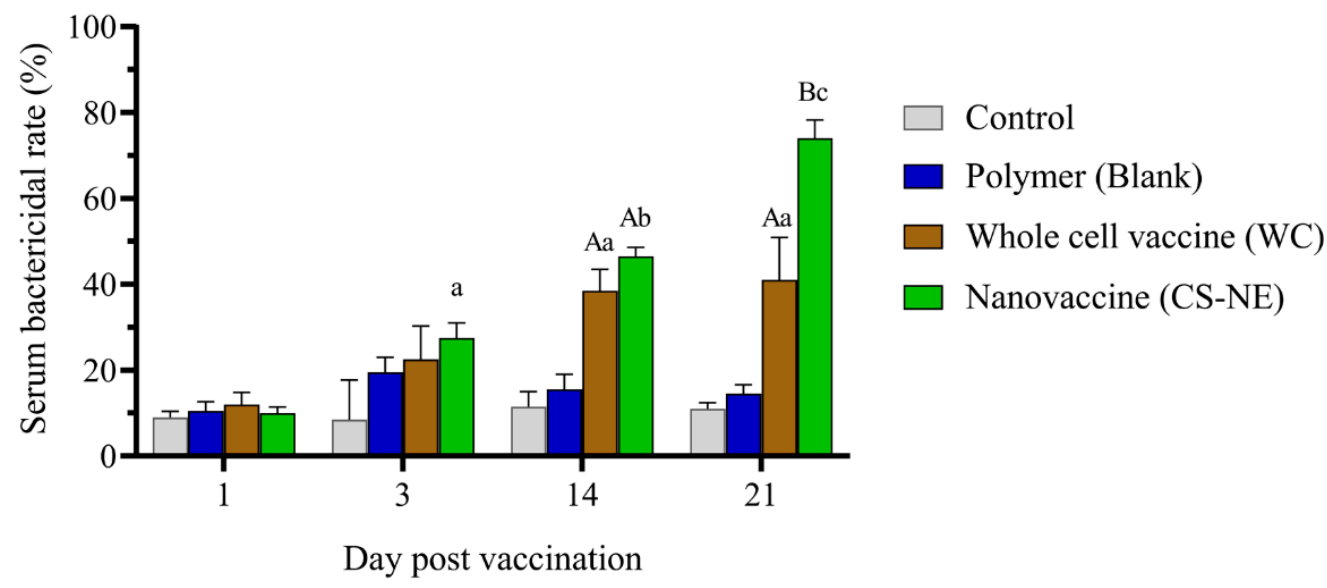

Figure 5. Serum bactericidal activity (SBA) of vaccinated fish. SBA of sera from CS-NE vaccinated were significantly higher than control groups at 1, 3, 14, and 21 days post-vaccination. Different capital letters indicate significant differences between groups at $p<0.05$ within each time point. Different small letters indicate significant differences over time within each group $(\mathrm{N}=6)$. Two-way analysis of variance, and repeated measures analysis of variance followed by Bonferroni's multiple comparison test were used for statistical analysis.

\subsection{Enzyme-Linked Immunosorbent Assay (ELISA)}

Serum samples were collected from each group to assess antibody levels at 1, 3, 14, and 21 days post-vaccination (6 fish/group/time), respectively. We found that tilapia sera were positive at 3, 14, and $21 \mathrm{dpv}$ in the WC and CE-NE groups, with sera from the CS-NE group having the highest OD value between all groups at $21 \mathrm{dpv}$. Specific IgM levels were significantly greater in vaccinated fish compared to control fish $(p<0.001)$ at 14 and $21 \mathrm{dpv}$ (Figure 6, Supplementary Table S4), and which was seen to increase between 14 and $21 \mathrm{dpv}$.

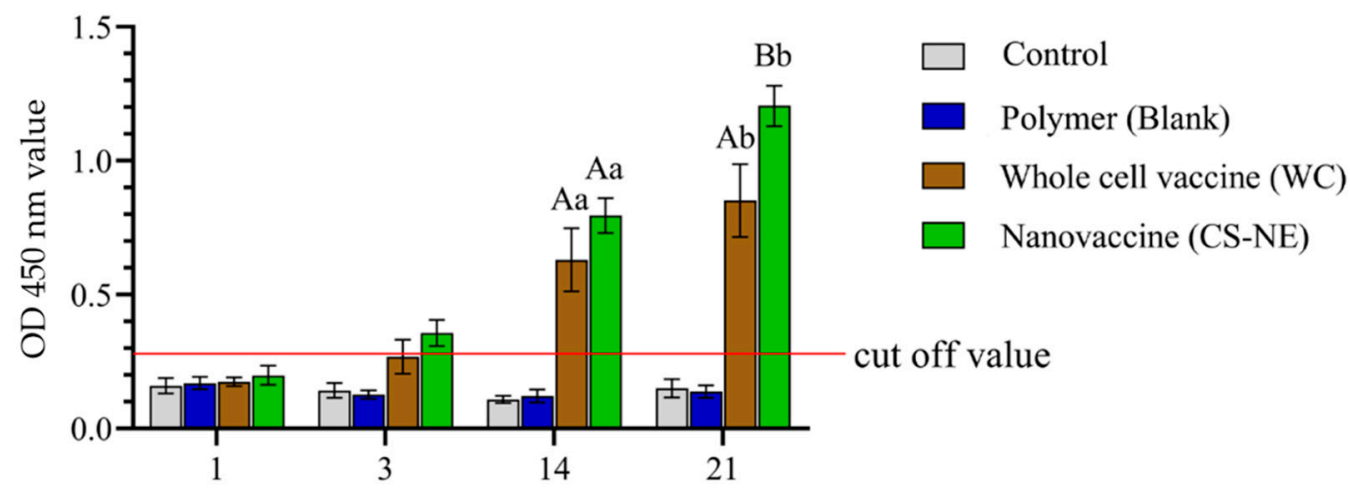

Day post vaccination

Figure 6. Identification of seropositive and seronegative fish amongst vaccine groups using an indirect ELISA. Different capital letters indicate significant differences at $p<0.05$ among groups at each time point. Different small letters indicate significant differences over time within each group $(\mathrm{N}=6)$. Two-way analysis of variance, and repeated measures analysis of variance followed by Bonferroni's multiple comparison test were used for statistical analysis.

\subsection{Gene Expression with RT-qPCR}

At $1,3,14$, and $21 \mathrm{dpv}$, the expression of 5 immune-related genes i.e., $\operatorname{IgM}, \operatorname{IgT}$, IL1 $\beta, T N F-\alpha$, and MHCI, was examined in the spleen and head kidney of fish from each experimental group. Expression of IgM, IgT, IL1 $\beta, T N F-\alpha$, and MHCI was significantly higher in the CS-NE group compared to the WC and polymer vaccinated groups (Figure 7, Supplementary Table S5). Genes encoding IgM, IgT, IL1 $\beta$, TNF- $\alpha$, and MHCI genes were also upregulated at each time point examined, especially in the CS-NE vaccinated group. 
The expression of $M H C I, T N F \alpha$, and IL-1 genes was highly upregulated at the early stage of vaccination induction ( 1 and $3 \mathrm{dpv}$ ) and gradually declined in both head kidney and spleen of vaccinated fish. This expression kinetics was clearly seen in the CS-NE vaccinated fish when compared to the control fish. The $\mathrm{MHCI}$ gene expression tended to be upregulated until $21 \mathrm{dpv}$ in the spleen of CS-NE vaccinated fish. The expression of IgT and IgM was also higher at the initial stages of vaccination in the head kidney of vaccinated fish in all groups and was reduced in the later stages of the trial $(21 \mathrm{dpv})$. However, the expression of IgM was consistently upregulated in the spleen of CS-NE vaccinated fish throughout the 21-day experimental period.

a. Head kidney

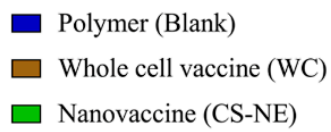

Nanovaccine (CS-NE)

Kidney: $T N F \alpha$

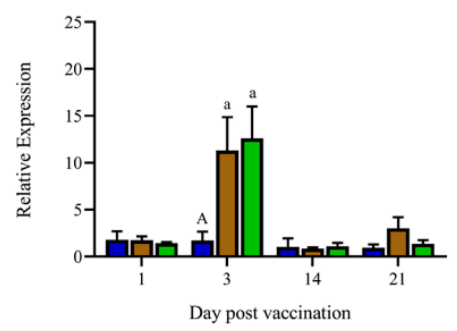

b. Spleen

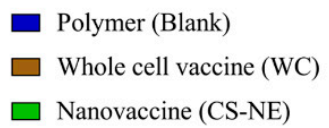

Nanovaccine (CS-NE)

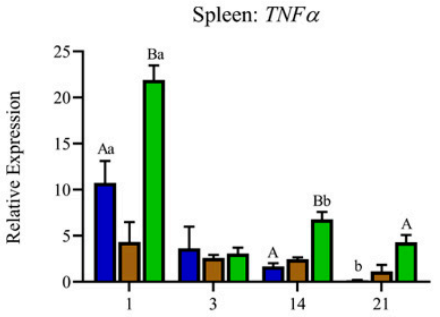

Day post vaccination

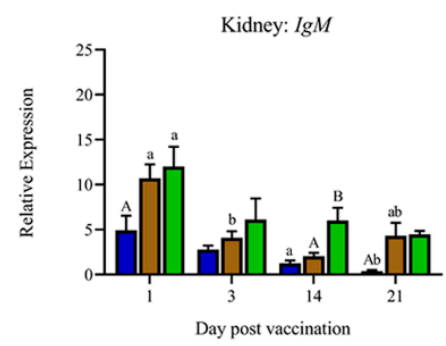

Kidney: $I L 1 \beta$

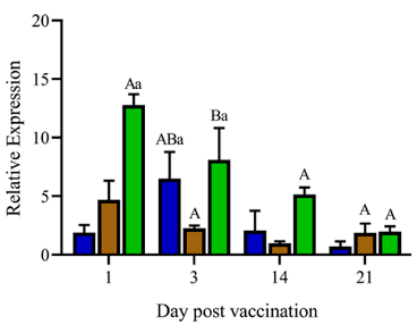

Spleen: $\operatorname{Ig} M$

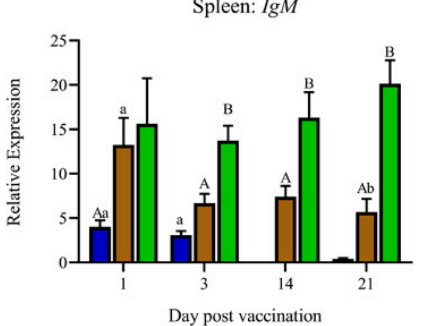

Spleen: $I L 1 \beta$

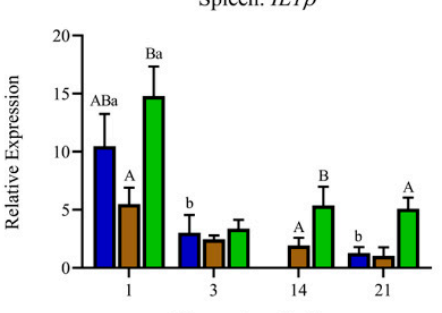

Day post vaccination

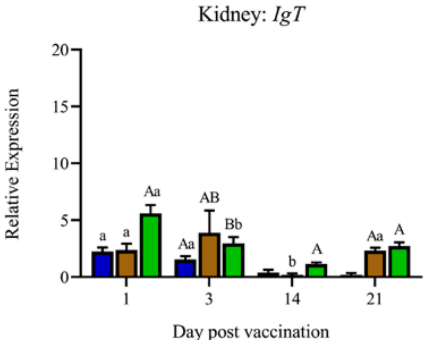

Kidney: $M H C I$

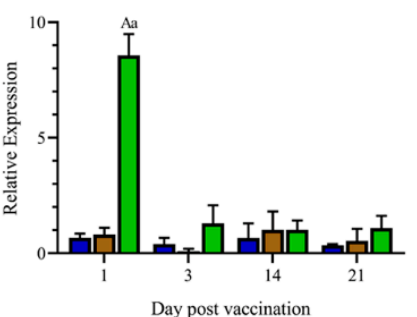

Spleen: $\operatorname{Ig} T$

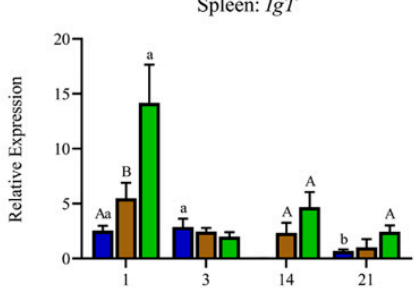

Day post vaccination

Spleen: $M H C I$

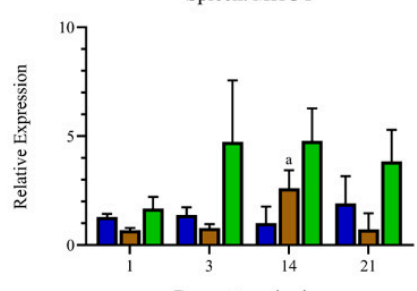

Day post vaccination

Figure 7. Gene expression of five immune genes- $\operatorname{Ig} M, \operatorname{Ig} T, \operatorname{IL1} \beta, T N F-\alpha$, and MHCI in the head kidney (a) and spleen (b) of vaccinated fish (CS-NE (green), WC (brown), Polymer (blue)) relative to unvaccinated control fish at 1,3,14, and 21 days post-vaccination. Different capital letters indicate significant differences at $p<0.05$ among groups at each time point. Different small letters indicate significant differences over time within each group $(\mathrm{N}=6)$. Two-way analysis of variance, and repeated measures analysis of variance followed by Bonferroni's multiple comparison test were used for statistical analysis. 


\section{Discussion}

An understanding of the adaptive immune response following vaccination is needed to develop a safe and efficacious vaccine against columnaris disease in tilapia, including knowledge on the specific antibody kinetics to the vaccine. Our previous study showed that a biomimetic mucoadhesive nanovaccine was able to activate the mucosal associated lymphoid tissues in vaccinated fish and generated a strong mucosal immune response against columnaris disease in the fish [4]. In this study, we investigated the specific antiF. columnare IgM response in tilapia immunized with the vaccine, together with their ability to resist experimental challenge with a virulent strain of $F$. columnare. Bactericidal serum activity and the use of an ELISA developed in-house were used as serological assays for evaluation of the systemic immune response in fish vaccinated with our mucosal deliverynanovaccine. This vaccine performed better than the WC immersion vaccine, reflected by the RPS values obtained after performing a $F$. columnare immersion challenge, with the biomimetic-mucoadhesive nanovaccine providing significantly better protection against the pathogen. This finding confirms the results of our previous study and the average percentage survival obtained with this vaccine in the two trials was $72-78 \%$ for immersion vaccinated tilapia held at $25-28{ }^{\circ} \mathrm{C}$ and challenged with $1.0 \times 10^{7}$ F. columnare $\mathrm{CFU}$ per fish, regardless of their age and size (average size of the fish used in previous study was $5 \mathrm{~g}$ compared with $100 \mathrm{~g}$ fish used in the present study).

The ELISA is recognized as a sensitive, widely used assay, reliable for the detection and quantification of specific humoral antibody responses to fish pathogens [25-27] including F. columnare $[8,11]$. In this study, the ELISA protocol was optimized and validated using positive and negative control serum. The positive serum samples were collected from tilapia experimentally infected with the pathogen, whereas the negative control sera were collected from the same fish prior to the challenge as well as non-challenge fish. Although very low $\mathrm{OD}$ values were observed in the negative control fish, this might be explained by non-specific binding associated with tilapia serum $[8,11,28]$. In fact, fish used in this study were not specific pathogen-free, and the possibility of pre-exposure to F. columnare could not be ruled out. Multiple factors can influence the dynamic patterns of the specific antibody responses obtained, such as the pathogen, type of vaccines used, the delivery method, and the inclusion of an adjuvant or delivery vehicles in the vaccine. For example, in one study, it was noted that the antibody response of tilapia vaccinated with a formalin killed the F. columnare vaccine containing Freund's complete adjuvant occurred within $14 \mathrm{dpv}$ and then gradually declined by 21 and $28 \mathrm{dpv}$ [11], while little or no antibody response was seen in Nile tilapia fingerlings receiving a $F$. columnare vaccine delivered by oral or immersion vaccination, again using formalin-killed bacteria [12]. Contrary to this, in rainbow trout, immersion vaccination is able to induce a high serum IgM antibody response up to 21 to $28 \mathrm{dpv}$, after which it is gradually reduced. A greater IgM response was detected in the skin mucus and persisted up to 4 to 6 weeks post-immersion vaccination with a live attenuated $F$. columnare vaccine, as well as a recombinant $F$. columnare DnaK protein vaccine [29]. In our study, we detected a rapid antibody response as early as 3-7 dpv, which were significantly higher at 14 to $21 \mathrm{dpv}$ in the CS-NE vaccinated tilapia. Peak antibody levels were reached by 21 days post-immersion vaccination. The study showed that vaccinated tilapia are capable of mounting a significant humoral immune response to F. columnare, but this was only seen when the bacteria were incorporated into the charged-mucoadhesive nano-delivery system.

Serum bactericidal activity has been used as a measure of complement-mediated activity in the presence of vaccine-induced antibodies. Although the evaluation of serum antibacterial activity is considered to be a non-specific response for inhibiting the growth of bacteria $[30,31]$, it is accepted as an in vitro correlate of protection for the evaluation of the immunogenicity of bacterial vaccines $[30,32,33]$. The increased serum bactericidal activity detected after immersion vaccination reflects the raise of protective proteins in the serum, including immunoglobulins, proteins of the complement system, acute phase proteins, cytokines, lysozyme, transferrin, and lectins that are usually induced or elevated after infec- 
tion or vaccination [31,34]. Humoral immune responses by ELISA-specific IgM antibodies were significantly higher in CS-NE vaccinated fish, in accordance with a significantly higher SBA, indicating stimulation of the immune response against $F$. columnare by the mucoadhesive nanovaccine. A rapid and robust method for assessing serum bactericidal activity may inform the best vaccine formulation, optimal dose, and schedule for a vaccine, and may be a useful part of evaluating large vaccine efficacy trials [35]. In our previous study [4], we showed evidence for a systemic cellular immune response, indicated by the hyperplasia of lymphoid cells in spleen and head kidney in the nanovaccine immunized group. Researchers demonstrated that lipid nanoparticles could induce $\mathrm{T}$ cell responses, regulating adaptive cell-mediated immunity, resulting in protection against intracellular pathogens [36-39]. However, due to the lack of molecular markers and antibodies to specifically identify $\mathrm{T}$ and $\mathrm{B}$ cells in tilapia, it is difficult to investigate the relationship between specific cellular immune responses elicited by the CS-NE vaccine and their role in protective systemic immune responses.

The nanovaccine modulated the expression of $T N F-\alpha$ or $I L 1 \beta$, two key pro-inflammatory cytokines that are crucial for coordinating cell-mediated immunity and play a critical role in modulating the immune system against $F$. columnare infection $[40,41]$. Our previous studies confirmed that macrophages, intra-epithelial lymphocytes, and eosinophilic granular cells are recruited to the sites of infection, with the aim of controlling and eradicating the F. columnare infection, as seen in MALT histopathology during the early stages of response to the infection ( $3 \mathrm{dpi}$ ) [4]. There is a complex interaction between innate and adaptive immune responses. The set of immune-related genes selected in the present study potentially reflect the complexity of this relationship. Upregulation of MHCI, TNF $\alpha$ and IL- 1 are mediators of the innate immune response, orchestrating the innate cell to respond to the infection, and activating the protective adaptive immune response. In this study, MHC-I gene expression was highly upregulated in the head kidney and spleen of the CS-NE vaccinated fish, suggesting the potential intracellular antigen presented by polymeric nanoparticles as mentioned by researchers [42,43]. Lipid nanoparticles are able to induce $\mathrm{T}$ cell responses and regulate adaptive cell-mediated immunity, resulting in protection against intracellular pathogens [36-39].

During initiation of adaptive immune mechanisms, early immune related gene expression responses are necessary, as they provide the first line of defense against the infection or vaccination [44], and we focused our study on 1 to $21 \mathrm{dpv}$, when development of the immune response was ongoing. The expression profile of immune related genes in lymphoid organs of vaccinated fish demonstrate the immunological cascade of antibody production by both IgM and IgT-producing B cells in response to the F. columnare immersion vaccination. Similar higher levels of immune gene expression were seen in spleen and head kidney of CS-NE vaccinated tilapia throughout the post-vaccination periods when compared with the other groups. A striking result of our study is the implication of B cells expressing $I g T$ and $I g M$ genes in the spleen in response to the immersion vaccination at $24 \mathrm{~h}$ post-vaccination and $24 \mathrm{~h}$ to $21 \mathrm{dpv}$, respectively. The results support the available information that immersion vaccination induces splenic and kidney IgT responses in tilapia. The question of the role of $I g T$ gene expression in the spleen of F. columnare-immersion vaccinated fish is intriguing. The dominant expression of the $\operatorname{IgM}$ and $\operatorname{IgT}$ transcripts in vaccinated fish and the increase of serum IgM concentration upon vaccination might indicate that the serum IgM and/or IgT antibodies were likely produced by splenic IgM or IgT producing cells, respectively. Alternatively, it might be speculated that specific IgT producing B cells may become activated and proliferate before migrating to the mucosal sites and may be found in the spleen as transiting cells [45]. IgT and IgM played an important role against $F$. columnare infection in gill mucosal and the systemic immunity of rainbow trout [44]. Due to a lack of available monoclonal antibodies against the IgT immunoglobulin class in tilapia, similar studies are limited in tilapia. Ideally, IgT-ELISA studies should be used to investigate the persistence of the immune response in fish vaccinated with the mucoadhesive nano-vaccine. We showed that CS-NE can induce tilapia 
IgT, and IgM responses in vaccinated fish and promote intracellular uptake by MHC-I, and regulate adaptive cell-mediated immunity to provide protection against $F$. columnare infection. However, the duration of protection and the anamnestic response of the $\operatorname{IgT}$ and IgM antibodies should be investigated after challenging or a booster vaccination over the lifespan of vaccinated tilapia. The reactivation of memory B cells in lymphoid organs by the chitosan-lipid based mucoadhesive nano-platforms should also be examined.

\section{Conclusions}

We applied an innovative nanotechnology to develop a mucosal vaccine delivery system suitable for improved immersion vaccination of tilapia. The biomimetic nanoparticles induced a strong humoral immune response, resulting in a significant increase in RPS against columnaris disease. The splenic IgM and IgT genes were highly upregulated, corresponding with higher serum IgM production and a greater serum bactericidal activity against the homologous challenge strain. The results confirm that the chargedmucoadhesive nanovaccine modified by a chitosan-based delivery is an effective alternative platform for immersion vaccination of tilapia, generating systemic immune responses against columnaris disease in tilapia.

Supplementary Materials: The following are available online at https://www.mdpi.com/article/ 10.3390/vaccines9111253/s1, Table S1: Standardization of the indirect ELISA, Table S2: A titration data (OD value at $450 \mathrm{~nm}$ ) for seronegative serum and seropositive, Table S3: The number of viable bacteria, Table S4: OD $450 \mathrm{~nm}$ value of serum samples from each group, Table S5: the expression of 5 immune-related genes was examined in the spleen and head kidney.

Author Contributions: N.P. and T.Y. were involved in the design and supervision of all experiments. N.P., S.K. and C.R. were involved in conducting the biological experiments including in vivo studies. S.K., T.K., T.Y., K.D.T., J.C., S.T., P.E. and K.N. performed the statistical analyses and wrote the manuscript text. All authors have read and agreed to the published version of the manuscript.

Funding: This research received the Second Century Fund, Chulalongkorn University (C2F scholarship), and the Bacterial Vaccines (BactiVac) Network funded by the GCRF Networks in Vaccines Research and Development, which was co-funded by the MRC and BBSRC.

Institutional Review Board Statement: This study was approved by the Institutional Biosafety Committee and the Institutional Animal Care and Use Committee of Faculty of Veterinary Science, Chulalongkorn University (IBC1831052; IACUC1831020).

Acknowledgments: This work was supported by the Second Century Fund, Chulalongkorn University (C2F scholarship), and the Bacterial Vaccines (BactiVac) Network funded by the GCRF Networks in Vaccines Research and Development, which was co-funded by the MRC and BBSRC.

Conflicts of Interest: The authors declare no conflict of interest.

\section{References}

1. LaFrentz, B.R.; García, J.C.; Waldbieser, G.C.; Evenhuis, J.P.; Loch, T.P.; Liles, M.R.; Wong, F.S.; Chang, S.F. Identification of Four Distinct Phylogenetic Groups in Flavobacterium columnare with Fish Host Associations. Front. Microbiol. 2018, 9, 452. [CrossRef]

2. Dong, H.T.; LaFrentz, B.; Pirarat, N.; Rodkhum, C. Phenotypic characterization and genetic diversity of Flavobacterium columnare isolated from red tilapia, Oreochromis sp., in Thailand. J. Fish Dis. 2014, 38, 901-913. [CrossRef]

3. Shoemaker, C.A.; LaFrentz, B.R. Growth and survival of the fish pathogenic bacterium, Flavobacterium columnare, in tilapia mucus and porcine gastric mucin. FEMS Microbiol. Lett. 2015, 362, 1-5. [CrossRef] [PubMed]

4. Kitiyodom, S.; Trullàs, C.; Rodkhum, C.; Thompson, K.D.; Katagiri, T.; Temisak, S.; Namdee, K.; Yata, T.; Pirarat, N. Modulation of the mucosal immune re-sponse of red tilapia (Oreochromis sp.) against columnaris disease using a biomimetic-mucoadhesive nanovaccine. Fish Shellfish. Immunol. 2021, 112, 81-91. [CrossRef]

5. Laanto, E.; Penttinen, R.K.; Bamford, J.K.; Sundberg, L.-R. Comparing the different morphotypes of a fish pathogen-Implications for key virulence factors in Flavobacterium columnare. BMC Microbiol. 2014, 14, 170. [CrossRef]

6. Fujihara, M.; Olson, P.; Nakatani, R. Some factors in susceptibility of juvenile rainbow trout and chinook salmon to Chondrococcus columnaris. J. Fish Res. Board Can. 1971, 28, 1739-1743. [CrossRef]

7. Moore, A.A.; Eimers, M.E.; Cardella, M.A. Attempts to ControlFlexibacter columnarisEpizootics in Pond-Reared Channel Catfish by Vaccination. J. Aquat. Anim. Health 1990, 2, 109-111. [CrossRef] 
8. Shoemaker, C.A.; Shelby, R.A.; Klesius, P.H. Development of an indirect ELISA to detect humoral response to Flavobacterium columnare infection of channel catfish, Ictalurus punctatus. J. Appl. Aquac. 2003, 14, 43-52. [CrossRef]

9. Mano, N.; Inui, T.; Arai, D.; Hirose, H.; Deguchi, Y. Immune Response in the Skin of Eel against Cytophaga columnaris. Fish Pathol. 1996, 31, 65-70. [CrossRef]

10. Liewes, E.; Van Dam, R.; Vos-Maas, M.; Bootsma, R. Presence of antigen sensitized leukocytes in carp (Cyprinus carpio L) follow-ing bath immunization against Flexibacter columnaris. Vet. Immunol. Immunopathol. 1982, 3, 603-609. [CrossRef]

11. Grabowski, L.; LaPatra, S.; Cain, K. Systemic and mucosal antibody response in tilapia, Oreochromis niloticus (L.), following im-munization with Flavobacterium columnare. J. Fish Dis. 2004, 27, 573-581. [CrossRef]

12. Leal, C.; Carvalho-Castro, G.; Sacchetin, P.; Lopes, C.; Moraes, A.; Figueiredo, H. Oral and parenteral vaccines against Flavobacterium columnare: Evaluation of humoral immune response by ELISA and in vivo efficiency in Nile tilapia (Oreochromis niloticus). Aquac. Int. 2010, 18, 657-666. [CrossRef]

13. Kitiyodom, S.; Yata, T.; Yostawornkul, J.; Kaewmalun, S.; Nittayasut, N.; Suktham, K.; Surassmo, S.; Namdee, K.; Rodkhum, C.; Pirarat, N. Enhanced efficacy of immersion vac-cination in tilapia against columnaris disease by chitosan-coated "pathogen-like" mucoadhesive nanovaccines. Fish Shellfish. Immunol. 2019, 95, 213-219. [CrossRef] [PubMed]

14. Kitiyodom, S.; Kaewmalun, S.; Nittayasut, N.; Suktham, K.; Surassmo, S.; Namdee, K.; Rodkhum, C.; Pirarat, N.; Yata, T. The potential of mucoadhesive polymer in enhancing efficacy of direct immersion vaccination against Flavobacterium columnare infection in tilapia. Fish Shellfish. Immunol. 2018, 86, 635-640. [CrossRef]

15. Austin, B. Developments in vaccination against fish bacterial disease. In Infectious Disease in Aquaculture; Woodhead Publishing: Sawston, UK, 2012; pp. 218-243. [CrossRef]

16. Zhu, W.; Yang, G.; Zhang, Y.; Yuan, J.; An, L. Generation of Biotechnology-Derived Flavobacterium columnare Ghosts by PhiX174 GeneE-Mediated Inactivation and the Potential as Vaccine Candidates against Infection in Grass Carp. J. Biomed. Biotechnol. 2012, 2012, 760730. [CrossRef] [PubMed]

17. Crowther, J.R. Validation of Diagnostic Tests for Infectious Diseases, The ELISA Guidebook; Humana Press: Totowa, NJ, USA, 2001; pp. 301-345. [CrossRef]

18. Pirarat, N.; Pinpimai, K.; Endo, M.; Katagiri, T.; Ponpornpisit, A.; Chansue, N.; Maita, M. Modulation of intestinal morphology and im-munity in nile tilapia (Oreochromis niloticus) by Lactobacillus rhamnosus GG. Vet. Sci. Res. J. 2011, 91, e92-e97. [CrossRef] [PubMed]

19. Livak, K.J.; Schmittgen, T.D. Analysis of relative gene expression data using real-time quantitative PCR and the $2-\Delta \Delta C T$ meth-od. Methods 2001, 25, 402-408. [CrossRef]

20. Pfaffl, M.W. A new mathematical model for relative quantification in real-time RT-PCR. Nucleic Acids Res. 2001, 29, e45. [CrossRef]

21. Zhang, C.; Lian, A.; Xu, Y.; Jiang, Q. Signal Transduction Mechanisms for Glucagon-Induced Somatolactin Secretion and Gene Expression in Nile Tilapia (Oreochromis niloticus) Pituitary Cells. Front. Endocrinol. 2021, 11, 629077. [CrossRef]

22. Zheng, Y.; Wu, W.; Hu, G.; Qiu, L.; Chen, J. Transcriptome Analysis of Juvenile Tilapia (Oreochromis niloticus) Blood, Fed with Different Concentrations of Resveratrol. Front. Physiol. 2020, 11, 600730. [CrossRef]

23. Sewaka, M.; Trullas, C.; Chotiko, A.; Rodkhum, C.; Chansue, N.; Boonanuntanasarn, S.; Pirarat, N. Efficacy of synbiotic Jerusalem artichoke and Lactobacillus rhamnosus GG-supplemented diets on growth performance, serum biochemical parameters, intestinal morphology, immune parameters and protection against Aeromonas veronii in juvenile red tilapia (Oreochromis spp.). Fish Shellfish Immunol. 2018, 86, 260-268. [CrossRef]

24. Mohammed, H.; Olivares-Fuster, O.; LaFrentz, S.; Arias, C.R. New attenuated vaccine against columnaris disease in fish: Choos-ing the right parental strain is critical for vaccine efficacy. Vaccine 2013, 31, 5276-5280. [CrossRef] [PubMed]

25. Ristow, S.; De Avila, J.; Lapatra, S.E.; Lauda, K. Detection and characterization of rainbow trout antibody against infectious hem-atopoietic necrosis virus. Dis. Aquat. Org. 1993, 15, 109-114. [CrossRef]

26. Romestand, B.; Dragesco, A.; Breuil, G.; Coste, F.; Bouix, G. An ELISA technique for rapid diagnosis of vibriosis in sea bass Dicentrarchus labrax. Dis. Aquat. Org. 1993, 15, 137-143. [CrossRef]

27. Xu, D.H.; Klesius, P. Protective effect of cutaneous antibody produced by channel catfish, Ictalurus punctatus (Rafinesque), im-mune to Ichthyophthirius multifiliis Fouquet on cohabited non-immune catfish. J. Fish Dis. 2003, 26, 287-291. [CrossRef]

28. Zhang, Y.; Arias, C.R.; Shoemaker, C.; Klesius, P.H. Comparison of lipopolysaccharide and protein profiles between Flavobacterium columnare strains from different genomovars. J. Fish Dis. 2006, 29, 657-663. [CrossRef]

29. Lange, M.D.; Abernathy, J.; Farmer, B.D. Evaluation of a Recombinant Flavobacterium columnare DnaK Protein Vaccine as a Means of Protection against Columnaris Disease in Channel Catfish (Ictalurus punctatus). Front. Immunol. 2019, 10, 1175. [CrossRef]

30. Rossi, O.; Molesti, E.; Saul, A.; Giannelli, C.; Micoli, F.; Necchi, F. Intra-Laboratory Evaluation of Luminescence Based HighThroughput Serum Bactericidal Assay (L-SBA) to Determine Bactericidal Activity of Human Sera against Shigella. High-Throughput 2020, 9, 14. [CrossRef] [PubMed]

31. Biller-Takahashi, J.; Takahashi, L.; Pilarski, F.; Sebastião, F.; Urbinati, E. Serum bactericidal activity as indicator of innate immunity in pacu Piaractus mesopotamicus (Holmberg, 1887). Arq. Bras. Med. Vet. Zootec. 2013, 65, 1745-1751. [CrossRef]

32. Borrow, R.; Carlone, G.; Rosenstein, N.; Blake, M.; Feavers, I.; Martin, D.; Zollinger, W.; Robbins, J.; Aaberge, I.; Granoff, D.M.; et al. Neisseria meningitidis group B correlates of protection and assay standardization-International meeting report Emory University, Atlanta, Georgia, United States, 16-17 March 2005. Vaccine 2006, 24, 5093-5107. [CrossRef] 
33. Ndungo, E.; Pasetti, M.F. Functional antibodies as immunological endpoints to evaluate protective immunity against Shigella. Hum. Vaccines Immunother. 2019, 16, 197-205. [CrossRef] [PubMed]

34. Necchi, F.; Saul, A.; Rondini, S. Development of a high-throughput method to evaluate serum bactericidal activity using bacte-rial ATP measurement as survival readout. PLoS ONE 2017, 12, e0172163. [CrossRef] [PubMed]

35. Munang'Andu, H.M.; Evensen, Ø. Correlates of protective immunity for fish vaccines. Fish Shellfish. Immunol. 2018, 85, 132-140. [CrossRef] [PubMed]

36. Pati, R.; Shevtsov, M.; Sonawane, A. Nanoparticle Vaccines against Infectious Diseases. Front. Immunol. 2018, 9, 2224. [CrossRef]

37. Brandtzaeg, P. Induction of secretory immunity and memory at mucosal surfaces. Vaccine 2007, 25, 5467-5484. [CrossRef] [PubMed]

38. Khan, I.; Saeed, K.; Khan, I. Nanoparticles: Properties, applications and toxicities. Arab. J Chem. 2019, 12, 908-931. [CrossRef]

39. Agnihotri, S.A.; Mallikarjuna, N.N.; Aminabhavi, T.M. Recent advances on chitosan-based micro-and nanoparticles in drug de-livery. J Control. Release 2004, 100, 5-28. [CrossRef]

40. Balm, P.H.M.; Van Lieshout, E.; Lokate, J.; Bonga, S.E.W. Bacterial lipopolysaccharide (LPS) and interleukin 1 (IL-1) exert multiple physiological effects in the tilapia Oreochromis mossambicus (Teleostei). J. Comp. Physiol. B 1995, 165, 85-92. [CrossRef] [PubMed]

41. Mantovani, A.; Dinarello, C.A.; Molgora, M.; Garlanda, C. Interleukin-1 and Related Cytokines in the Regulation of Inflammation and Immunity. Immunity 2019, 50, 778-795. [CrossRef] [PubMed]

42. Tanaka, Y.; Taneichi, M.; Kasai, M.; Kakiuchi, T.; Uchida, T. Liposome-Coupled Antigens Are Internalized by Antigen-Presenting Cells via Pinocytosis and Cross-Presented to CD8+ T Cells. PLoS ONE 2010, 5, e15225. [CrossRef] [PubMed]

43. Welker, T.L.; Shoemaker, C.A.; Arias, C.R.; Klesius, P.H. Transmission and detection of Flavobacterium columnare in channel catfish Ictalurus punctatus. Dis. Aquat. Org. 2005, 63, 129-138. [CrossRef] [PubMed]

44. Tongsri, P.; Meng, K.; Liu, X.; Wu, Z.; Yin, G.; Wang, Q.; Liu, M.; Xu, Z. The predominant role of mucosal immunoglobulin IgT in the gills of rainbow trout (Oncorhynchus mykiss) after infection with Flavobacterium columnare. Fish Shellfish. Immunol. 2020, 99, 654-662. [CrossRef] [PubMed]

45. Castro, R.; Jouneau, L.; Pham, H.-P.; Bouchez, O.; Giudicelli, V.; Lefranc, M.-P.; Quillet, E.; Benmansour, A.; Cazals, F.; Six, A.; et al. Teleost Fish Mount Complex Clonal IgM and IgT Responses in Spleen upon Systemic Viral Infection. PLoS Pathog. 2013, 9, e1003098. [CrossRef] [PubMed] 